\title{
Fabrication of low cost and low impact RH and temperature sensors for the Internet of Environmental-Friendly Things
}

\author{
Aniello Falco ${ }^{1}$, Philipp S. Sackenheim ${ }^{2}$, Francisco J. Romero ${ }^{3}$, Markus Becherer ${ }^{2}$, Paolo \\ Lugli $^{1}$, José F. Salmerón ${ }^{3}$, Almudena Rivadeneyra ${ }^{3, *}$ \\ ${ }^{1}$ Faculty of Science and Technology, Free University of Bolzano, 39100 Bolzano-Bozen, Italy \\ ${ }^{2}$ Institute for Nanoelectronics, Technical University of Munich, 80333 Munich, Germany \\ ${ }^{3}$ Pervasive Electronics Advanced Research Laboratory (PEARL), Department of Electronics and Computer \\ Technology, University of Granada, 18071 Granada, Spain \\ Corresponding author. Tel: +34958248996. E-mail: arivadeneyra@ugr.es
}

Abstract- Given the increasing number of connected devices as a consequence of the Internet of Things (IoT) revolution, the issue of the removal and recycling of electronics is becoming more and more urgent. In this context, biodegradable electronics is expected to be one of the biggest technological revolutions to tackle this problem. Following this direction, in this work we present the fabrication and characterization of temperature and humidity sensors based on biodegradable materials with the goal of making their removal easier as well as reducing their environmental impact. In particular, these multi-sensing devices were fabricated following a screen-printing process using a carbon-based paste and a conjugated polymer, both on paper and on a water soluble substrate. The results are more than promising and show how with our biodegradable sensors it is possible to obtain a sensitivity of $1 \mathrm{dec} / 20 \% \mathrm{RH}$ to moisture content and around $0.04 \% /{ }^{\circ} \mathrm{C}$ sensitivity to temperature. It is demonstrated that the simplicity and flexibility of the fabrication approach followed in this work paves the way to a set of new "green" IoT nodes that could be extended to wide range of sensing applications.

Keywords: carbon; humidity; paper; PVA; PEDOT:PSS; screen-printing; temperature

\section{Introduction}

Sensing technologies are one of the key fields in both consumer electronics and industrial environment. Today we are measuring everything; sensors are in cars, buildings, cell phones, watches, and many other things of our daily life. Thus, this trend towards an ubiquitous sensing has made that the research and development in this field becomes particularly interesting.

Humidity sensors are among the most studied in this area since they play a key role in several areas, such as agriculture, food industry or healthcare (e.g., pharmaceutical \& bio-tech 
fabrication) [1], [2]. Humidity sensors are usually capacitive or resistive and, although there are further variations, they differ from others mainly in their preciseness, time response, size and costs [3]. However, given the circumstances imposed by the new technological applications, further aspects are becoming of special interest for their development, such as flexibility, biocompatibility or easy disposability [4]-[6]. This has led the novel fabrication methods to be focused not only on a highly scalable and economic production of devices, but also on their biodegradability in order to minimize, or even eliminate, their impact on the environment [7].

Printed sensors step exactly in this demand, as they allow the fabrication of cost-effective sensors based on fully biodegradable conductive pastes, sensitive materials and substrates [8], [9]. Therefore, several printable and organic materials have been proposed in this direction, such as conjugated polymers [9], graphene-based materials [10]-[12] and carbon-based pastes [13]. In the same way, different flexible substrates have also been used to deposit these materials, including paper [14]-[16] or liquid crystal polymers [17], [18], among others [19], [20].

Many of these materials and substrates has been already studied to develop temperature and humidity sensors, however, most of the implementations proposed in the literature resort to non-biodegradable materials to develop some elements of the final devices. For instance, Khan et al. presented a printed humidity sensor based on an egg albumin sensitive layer, but using silver electrodes on a PET substrate [21]. This approach was also followed in [22] and [12] using graphene oxide as sensitive layer and, in general, it can be found in many other works with different kind of materials [21], [23], [24]. Alternatively, Alrammouz et al. proposed a capacitive humidity sensor based on self-assembled graphene oxide sheets on a paper substrate, but with the drawback of using electrodes made of aluminum [25].

Within this context, in this work we present the fabrication and characterization of flexible humidity and temperature sensors by means of printing techniques and biodegradable materials (for both electrode and substrate) that are fully compatible with a cost-effective fabrication of eco-friendly devices. For that, a simple screen-printing process was used, demonstrating the feasibility of this approach through the combination of different conductive pastes and substrates. On one hand, we used standard paper as substrate since, in addition to being compatible with printing techniques and providing flexibility, its hydrophilic nature makes it a perfect candidate to act as a sensing material in RH sensors [26]-[28]. On the other hand, polyvinyl alcohol (PVA) films were also used for this purpose, given that the dielectric and conductive properties of this hygroscopic polymer change when the hydroxyl groups $(\mathrm{O}-\mathrm{H})$ of 
its structure interact with the water molecules [29]. These two substrates were used to print on them different electrodes configurations also using fully biodegradable conductive materials, specifically poly(3,4-ethylenedioxythiophene) polystyrene sulfonate (PEDOT:PSS) and a carbon-based paste. Each possible combination of these two conductive pastes and substrate materials was fabricated and characterized.

The manuscript is structured as follows: following this introduction, Section 2 summarizes the materials used for the fabrication of the sensors, together with the methodologies followed for their characterization. Section 3 presents the results of the temperature and humidity sensors fabricated, as well as a hybrid configuration to monitor both temperature and humidity on the same device. Finally, the main conclusions are drawn in Section 4.

\section{Experimental Section}

\subsection{Materials}

Two conductive inks were used for the fabrication of the printed sensors, poly(3,4ethylenedioxythiophene)-poly(styrenesulfonate) (PEDOT:PSS) and a commercial carbonbased paste, both of them providing flexibility and biodegradability. PEDOT:PSS at a weight content of 1.3 wt.\% (viscosity: >14000 mPa.s) was acquired from Sigma Aldrich (St. Louis, MO, USA) [30], while the Loctite ECI 8001 E\&C carbon-based paste (viscosity: 6500 mPa.s) was provided by Henkel AG (Düsseldorf, Germany) [31]. These pastes were printed on three different substrates: standard paper (DIN ISO 9706, 80g/m²) [32], polyvinyl alcohol (PVA) films from Wagner Polymertechnik GmbH, and polyethylene terephthalate (PET) foils from DuPont (product name: Melinex® ${ }^{\circledR}$ 506, Wilmington, DE, USA) [33]. This latter only for comparison and control since it is not biodegradable.

\subsection{Devices Fabrication}

A capacitive Interdigitated Electrode (IDE) structure was considered for the RH monitoring devices. Given that the dependence of the dielectric constant of the substrates with respect to the RH, the capacitance of these structures is also subject to the level of RH [34]. The advantage of the IDE layout lays in the simplicity of its geometry, and therefore, its easy application via printing on the flexible substrates [35]. After optimizing the four combination of pastes and substrates by printing lines of several widths, the combination carbon on PVA-L limited the resolution of our patterns with $800 \mu \mathrm{m}$ as minimal reproducible dimension. The IDE structure used in work (Figure 1) has 10 fingers per electrode with a distance between consecutive fingers 
and width of $1 \mathrm{~mm}$. These dimensions are large enough to minimize the possible effects on the capacitance as a consequence of the paste spreading over the substrate after the screen-printing process. Moreover, given that the resistivity of both of the conductive pastes used is temperature-dependent [31], [36], we opted for a resistive sensor for the temperature monitoring which consisted of a simple line with a length of $5 \mathrm{~cm}$. In addition, in order study the change in resistance with respect to the temperature (sensitivity and hysteresis) at different average resistances, we tested two different lines widths ( $3 \mathrm{~mm}$ and $5 \mathrm{~mm}$ ), as it is shown in Figure 1.

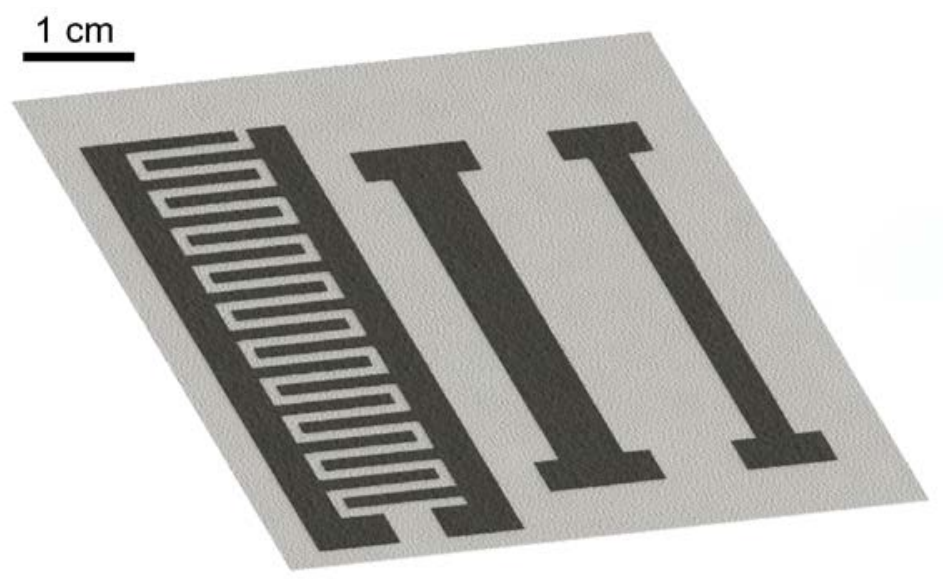

Figure 1. Left: Capacitive IDE layout. Right: Resistive line layouts with the same length $(5 \mathrm{~cm})$ and different widths (5 $\mathrm{mm}$ and $3 \mathrm{~mm}$ ).

These layouts were screen-printed with the different pastes on the different substrates with a manual screen-printer (FLAT-DX200, from Siebdruck-Versand, Magdeburg, Germany). Before printing, the PET substrate was washed using deionized water and ethanol with the assistance of ultrasonic treatment in order to remove the impurities on the surface [37]. Moreover, pressurized air was applied to the paper substrate with the same purpose, whereas no cleaning process was carried out for the PVA films. No pretreatment was needed to screen printing the pastes on any of the substrates. The mesh used in this work was a 120 Threads per $\mathrm{cm}(\mathrm{T} / \mathrm{cm})$ polyester mesh with a thickness of $65 \mu \mathrm{m}$, a thread diameter of $40 \mu \mathrm{m}$ and an opening width of $47 \mu \mathrm{m}$ which, according to the manufacturer, results in a theoretical wet film thickness of $t_{\text {theo }}=19.5 \mu \mathrm{m}$. After printing, the samples were dried using a UF55 oven (from Memmert, Schwabach, Germany) at $80{ }^{\circ} \mathrm{C}$ in order to avoid the degradation of the substrates. We also considered two different curing times, $30 \mathrm{~min}$ and $60 \mathrm{~min}$, to evaluate the influence of the drying process in the conductivity of the screen-printed patterns. 


\subsection{Characterization}

118 The sheet resistance of the conductive layers was measured using a four-point probe head from

119 Jandel (Leighton Buzzard, UK) connected to a source measuring unit (Keysight B2901A, 120 Beaverton, OR, USA). The thickness of the samples was acquired using a DekTak XT contact 121 profilometer (from Bruker Corporation, Billerica, MA, USA).

122 The characterization of the sensors under different environmental conditions (temperature and 123 humidity) was performed using the setup shown in Figure 2. The sensors were connected to an 124 impedance analyzer E4991A using a 42941A impedance probe kit (both from Keysight 125 Technologies, Inc., CA, USA). Afterwards, each connected sensor was placed into a climate 126 chamber VCL4006 (from Vötsch Industrietechnik GmbH, Balingen, Germany) and its 127 impedance was measured from $1 \mathrm{kHz}$ to $10 \mathrm{MHz}$ under different values of temperature and 128 humidity. The whole measurement setup was automatized using LabVIEW 2017 (from 129 National Instruments Corporation, TX, USA).

130

131

132

133

134

135

136

137 138

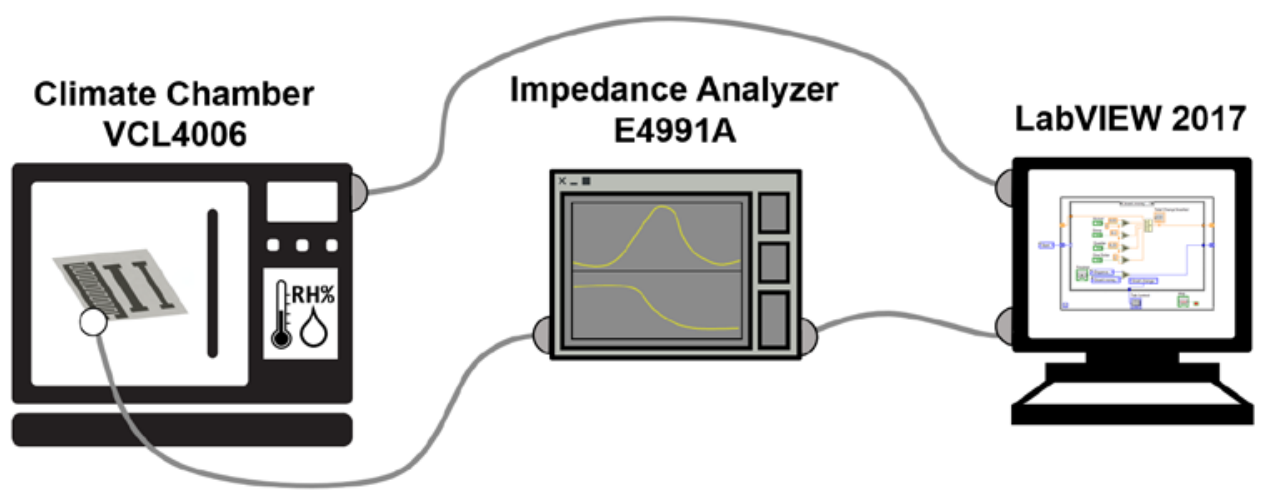

Figure 2. Characterization setup for humidity and temperature sensors.

The humidity sensors were tested as a function of both variating humidity and temperature. Firstly, the humidity sensors were characterized ranging the relative humidity level from $20 \% \mathrm{RH}$ to $70 \% \mathrm{RH}$ and vice versa at a temperature of $40{ }^{\circ} \mathrm{C}$. $\mathrm{RH}$ was changed in steps of $10 \% \mathrm{RH}$ every 30 min to ensure the uniformity of RH value in the whole chamber's volume. Secondly, both sensors (resistive and capacitive) were characterized as a function of the temperature. For that, it was ranged from $15{ }^{\circ} \mathrm{C}$ to $75{ }^{\circ} \mathrm{C}$ and vice versa at a fixed $60 \% \mathrm{RH}$. In this case, the temperature was varied in steps of $5{ }^{\circ} \mathrm{C}$ every $20 \mathrm{~min}$. 


\section{Results and Discussion}

140 Throughout this section, we show the results obtained for the characterization of both humidity

141 and temperature sensors fabricated with the biodegradable carbon-based and PEDOT:PSS pastes on both paper and PVA films. The results are also compared with respect to those obtained using PET as substrate of reference.

\subsection{Physical Characterization}

145

All the fully-biodegradable RH sensors fabricated in this work are shown in Figure 3. After visual inspection, it can be clearly observed that all inks were properly transferred to the substrates, except for the carbon-based paste on the PVA substrate (Figure 3d). In that case, the printing of the carbon paste (with a thickness of $10 \pm 1.2 \mu \mathrm{m}$ ) on the thin PVA substrate (30 $\mu \mathrm{m}$ ) produces a non-flexible device. Thus, when this device is bent, cracks appear on the whole carbon layer surface. However, this does not happen on the paper substrate, whose surface roughness and greater thickness $(\sim 100 \mu \mathrm{m})$ enhance the adhesion of the carbon-paste (Figure 3c). On the contrary, the PEDOT:PSS layer, which is thinner (2 $\pm 0.3 \mu \mathrm{m})$, presents a good adhesion and flexibility on both paper and PVA substrates.

(a)

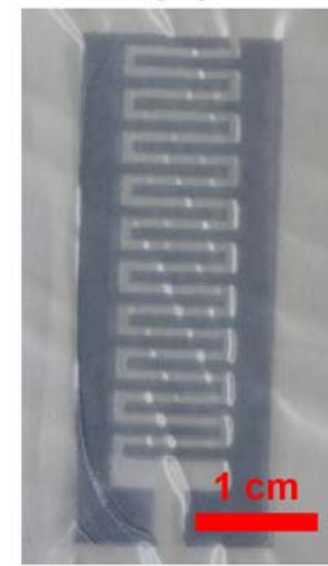

(b)

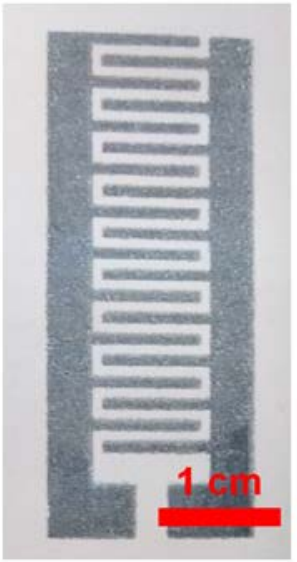

(c)

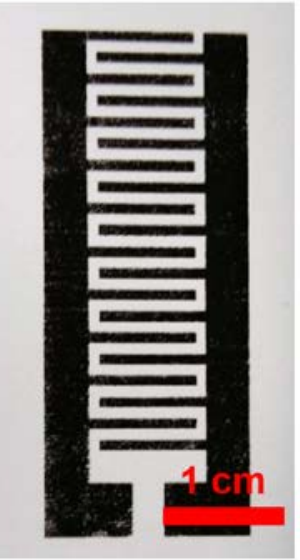

(d)

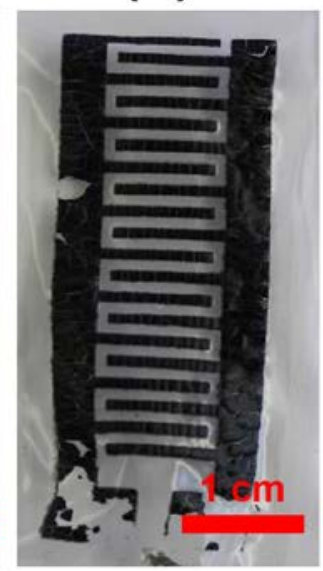

Figure 3. Real view of the screen-printed sensors: (a) PEDOT:PSS on PVA, (b) PEDOT:PSS on paper, (c) carbonbased paste on paper and (d) carbon-based paste on PVA. Scale bars: $1 \mathrm{~cm}$.

157 The sheet resistances of each one of these patterns are presented in Table 1 for the different 158 curing conditions. These values were obtained at ambient conditions, whereas errors were 159 calculated as the standard deviation of five different samples. As seen, any substantial variation 160 was observed when increasing the curing time. These values are also in accordance with respect 
161 to the obtained in other works, both for PEDOT:PSS [38]-[40] and for carbon-based pastes $162[41]$.

163

164

165

166

Table 1. Sheet resistance values for the different pastes and substrates under different curing conditions.

\begin{tabular}{|c|c|c|c|}
\hline Paste & Substrate & $\begin{array}{l}\text { Sheet Resistance }(\mathrm{k} \Omega / \mathrm{sq} .) \\
\text { (curing: } 30 \mathrm{~min} \text { at } 80^{\circ} \mathrm{C} \text { ) }\end{array}$ & 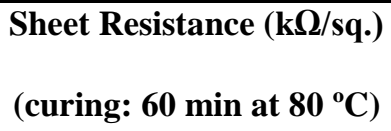 \\
\hline \multirow{2}{*}{ Carbon } & Paper & $3.84 \pm 0.86$ & $3.73 \pm 0.84$ \\
\hline & PVA & $3.89 \pm 0.93$ & $3.85 \pm 0.93$ \\
\hline \multirow{2}{*}{ PEDOT:PSS } & Paper & $1.20 \pm 0.13$ & $1.09 \pm 0.08$ \\
\hline & PVA & $1.21 \pm 0.16$ & $1.09 \pm 0.09$ \\
\hline
\end{tabular}

167

\subsection{Characterization in relative humidity}

169 Firstly, we characterized the impedance of the capacitive humidity sensors as a function of the 170 RH. The results of these experiments are shown in Figure 4 for the PEDOT:PSS IDEs and in 171 Figure 5 for the carbon-based ones. Reference calibration curves on PET can be found in 172 supplementary Figure S1 and Figure S2, respectively.

173 On one side, the impedance of both carbon paste and PEDOT:PSS on PET shows no

174 dependence on RH at any of the studied frequencies. In that case, the modulus and phase of the 175 impedance remain almost constant for the different values of $\mathrm{RH}$ and decrease as the frequency 176 increases. In the case of the phase, the decrease is less abrupt and, as capacitive structure, it is 177 around $-90^{\circ}$ [42]. On the other side, it can be seen in Figure 4 that the same capacitive structure 178 behaves differently on the other substrates. At low RH values, both on paper and PVA, the 179 PEDOT:PSS structures behave as a capacitor (phase close to $-90^{\circ}$ ). However, as $\mathrm{RH}$ increases, 180 the phase decreases indicating an increase in the capacitor dissipation factor. This phenomenon 181 can be related to an increase in the polymer conductivity as a consequence of the moisture 182 accumulation on the sensing layer (i.e., the substrate), hence causing the apparition of electrical 
184 like a resistor (phase closer to $0^{\circ}$ ) than like a capacitor [42].

185

186 187

188 (a)

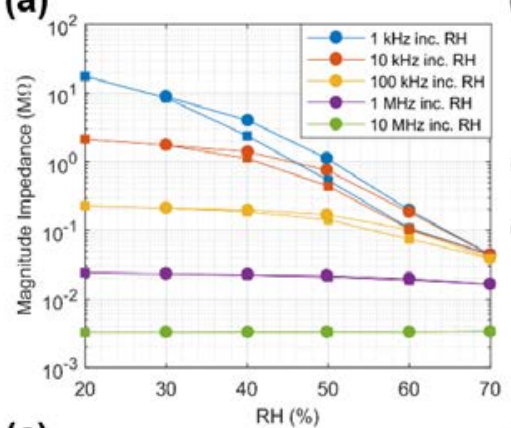

(c)

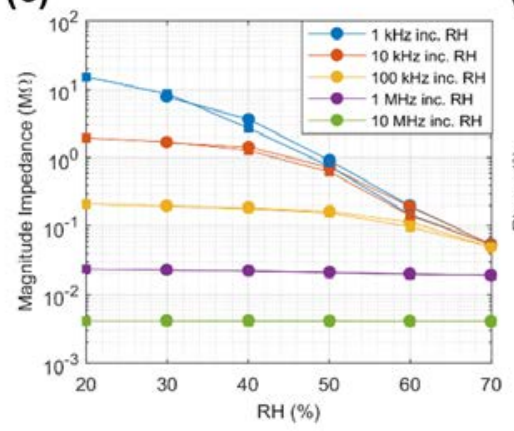

(b)

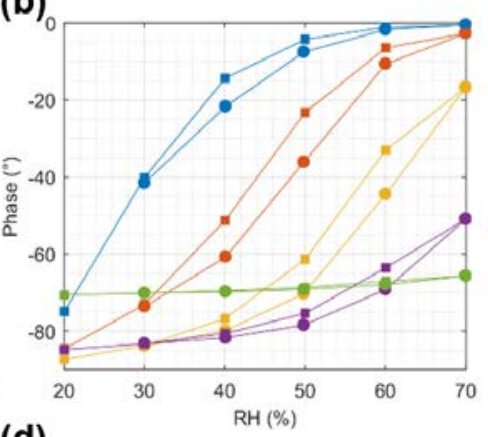

(d)

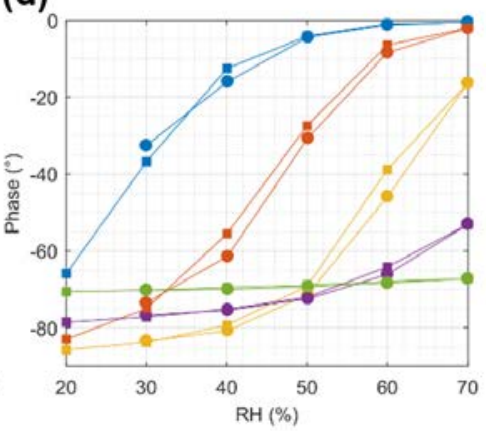

Figure 4. Impedance of the PEDOT:PSS IDEs on paper (magnitude: (a), phase: (b)) and on PVA (magnitude: (c), phase: (d)).

(a)

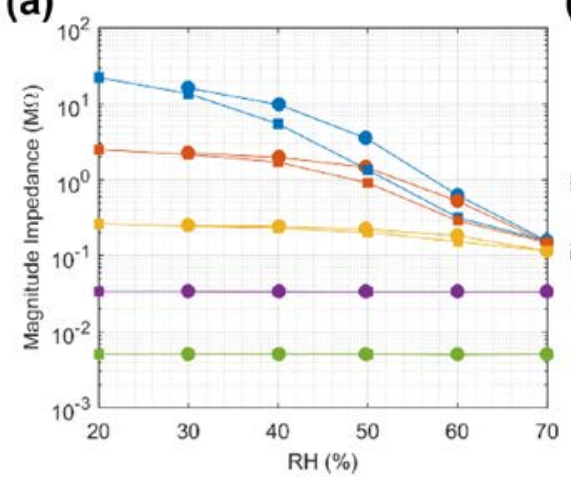

(b) $0-1 \mathrm{kHzinc}$ RH

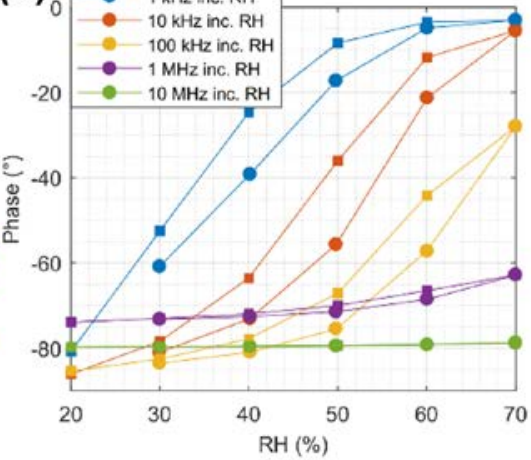

Figure 5. Impedance of the carbon IDEs on paper (magnitude: (a), phase: (b)).

Moreover, this behavior is similar to that obtained for the carbon-based IDEs on paper, as shown in Figure 5, which supports the theory that dependence with respect to the RH arises mainly from the properties of the sensing layer [43]. Finally, Figure S3 shows the results obtained for the the carbon- based paste on PVA, which demonstrates the non-viability of this combination for screen-printing (as it was shown in Section 3.1). 
In general, in all cases a sensitivity as high as $1 \mathrm{dec} / 20 \% \mathrm{RH}$ can be reproducibly achieved. In

197 all the analyzed combination of materials, the impedance changes abruptly from 20 to $60 \% \mathrm{RH}$ and then its responses is saturated. This behaviour is particularly significant up to $100 \mathrm{kHz}$. At low $\mathrm{RH}$ values, the devices are mainly capacitive (phase $<80^{\circ}$ ) and when $\mathrm{RH}$ increases, their phases decrease, achieving phases above $-10^{\circ}$ at $60 \% \mathrm{RH}$ (mainly resistive). However, there are differences related to the hysteresis of the sensors, the lowest value (below 3\%) is found for PEDOT:PSS IDES on PVA, followed by PEDOT:PSS on paper (5\%). In general, as it can be seen in Figure 4 and Figure 5, the paper substrate results in a higher hysteresis than the case of the PVA substrate.

Regarding the dynamic response of the sensors, we define the response time as $t=\tau$, which corresponds to the $63 \%$ of the maximum value of magnitude reached at equilibrium (for every increasing step of $\mathrm{RH}$ ). Table 2 summarizes the response time for each one of the analysed devices.

Table 2. Time response for RH

\begin{tabular}{ccc}
\hline Substrate & Time response of PEDOT:PSS IDES (min) & Time response of Carbon IDES (min) \\
\hline PVA & 5.8 & 6.5 \\
\hline Paper & 4.6 & 4.8
\end{tabular}

\subsection{Characterization in Temperature}

212 As it was already introduced, the resistivity of both PEDOT:PSS and carbon-based pastes used 213 in this work is temperature-dependent. In the case of the PEDOT:PSS, it exhibits a Negative 214 Temperature Coefficient (NTC) [36], [44], whereas the Loctite ECI 8001 E\&C paste is a 215 Positive Temperature Coefficient (PTC) ink [31]. On this basis, we characterized the impedance 216 of the resistive patterns as a function of the temperature on a paper substrate. Looking at the 217 behavior of single lines on paper using the same conductive materials (Fig. 6), we found that 218 PEDOT:PSS showed a relative linear response at $1 \mathrm{kHz}$ in the temperature range analyzed, as 219 it was also demonstrated in other works [45], [46]. These sensors exhibited a sensitivity of 220 around $0.04 \% /{ }^{\circ} \mathrm{C}$ and $0.03 \% /{ }^{\circ} \mathrm{C}$ (considering the relative resistance change as output variable) 221 for the $3 \mathrm{~mm}$ and $5 \mathrm{~mm}$ lines width, respectively. Contrary to this, carbon lines exhibited a quite 222 linear response at low temperatures, but surpassing the $\sim 50{ }^{\circ} \mathrm{C}$ their resistivity presented a sharp step response. It can be also seen that the response of the carbon-based paste presents a higher 
224 hysteresis than the PEDOT:PSS paste. These two effect are in accordance with the data 225 provided by the manufacturer [31].

226 For these structures, the sensitivity can be estimated as $3 \% /{ }^{\circ} \mathrm{C}$, which is significantly high enough to be easy detectable with any low-cost measurement equipment. Furthermore, the results obtained for the lines with $5 \mathrm{~mm}$ of width (supplementary Figure S4) showed that, while the temperature response and hysteresis of the PEDOT:PSS patterns does not suffer significant changes, the hysteresis presented by the carbon-based paste is reduced as a consequence of the overall reduction of the pattern resistance.
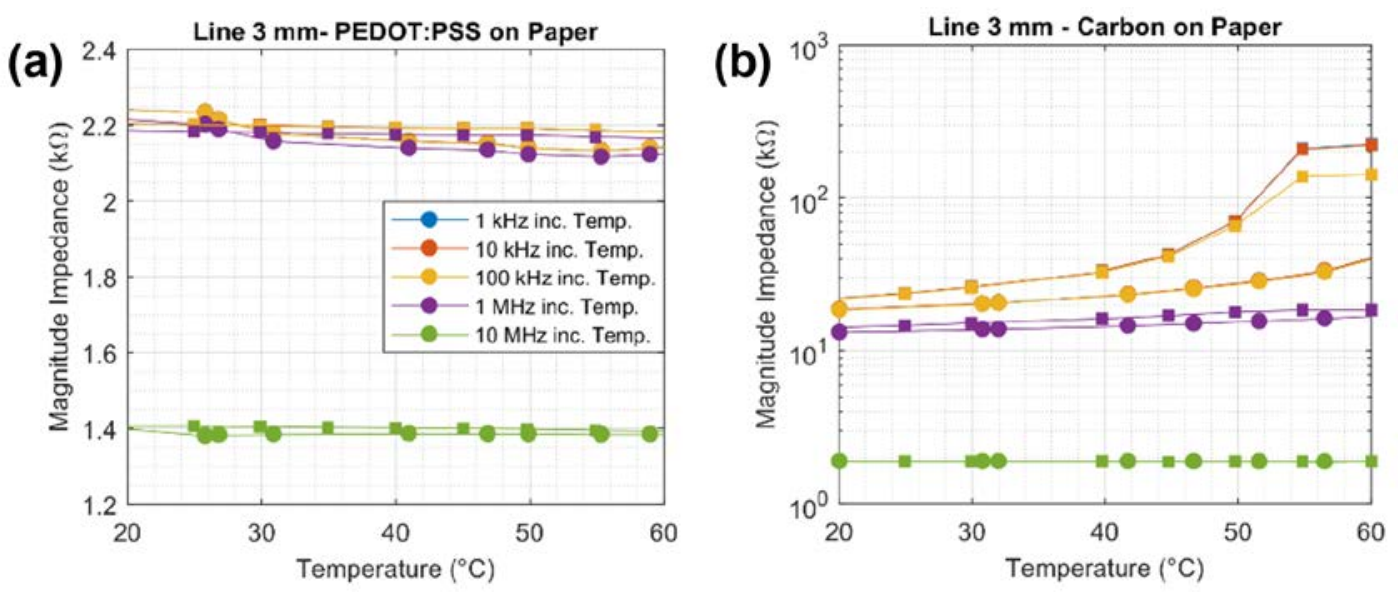

Figure 6. Impedance vs. temperature at different working frequencies of lines on paper made of PEDOT:PSS and Carbon with width of $3 \mathrm{~mm}$.

Regarding the dynamic response of the sensors and following the same definition as the one employed for $\mathrm{RH}$, Table 3 depicts the response time for each sensor characterized.

Table 3. Time response for Temperature

\begin{tabular}{ccc}
\hline Substrate & Time response of PEDOT:PSS IDES (min) & Time response of Carbon IDES (min) \\
\hline PVA & 3.9 & 3.3 \\
\hline Paper & 4.5 & 3.8 \\
\hline
\end{tabular}

\subsection{Comparison with similar sensors in the literature}

240 In this section, we compare the sensors proposed in this work with other fully biodegradable 241 sensors presented in the literature. The comparison was made in terms of type of sensor, 242 materials, fabrication process, area and sensitivity to the variable to monitor (temperature or 
243 humidity), as presented in Table 4. In recent years, novel approaches on carbon nanotubes 244 (CNTs) in their various forms, single-wallet and multi-wallet (SWCNTs, MWCNTs), are 245 positioning this material among the most promising materials for the development of 246 biodegradable sensors [47]. For instance, Liakos et al. [48] and Zhu et al. [49] used this 247 conductive organic material to fabricate humidity sensors on different biodegradable substrates, 248 achieving a quite similar sensitivity to humidity changes. However, although these sensors also 249 provide interesting features such as flexibility, their fabrication processes do not allow to pattern 250 surface of the substrates in order to optimize the sensing area. Contrary to this, printing 251 techniques are able to transfer different kind of layouts on the substrates, such as the capacitive 252 structures presented in this work, which allows to enhance the sensitivity of humidity sensors 253 more than two orders of magnitude. In addition, some of the presented processes are not suitable 254 for a large-scale and cost-effective production of devices, as it is de case of the one presented 255 in [49].

Table 4. Comparison with other biodegradable sensors.

\begin{tabular}{|c|c|c|c|c|c|}
\hline Reference & Sensor Type & $\begin{array}{c}\text { Electrode and } \\
\text { Substrate Materials }\end{array}$ & Fabrication Process & $\begin{array}{l}\text { Area } \\
\left(\mathrm{cm}^{2}\right)\end{array}$ & $\begin{array}{c}\text { Sensitivity } \\
\left(\Delta|\mathbf{Z}| /^{\circ} \mathbf{C} \text { or } \Delta|\mathbf{Z}| / \% \text { RH }\right. \\
)\end{array}$ \\
\hline $\begin{array}{l}\text { Salvatore et } \\
\text { al. [50] }\end{array}$ & Temperature & Mg/EcoFlex & $\begin{array}{l}\text { UV lithography / } \\
\text { etching }\end{array}$ & 7 & $70 \Omega /{ }^{\circ} \mathrm{C}$ \\
\hline $\begin{array}{l}\text { Yi et al. } \\
\text { [51] }\end{array}$ & Temperature & Zn/Galactomannan & Drop Casting & $\sim 0.5$ & $5 \Omega /{ }^{\circ} \mathrm{C}$ \\
\hline $\begin{array}{l}\text { Liakos et } \\
\text { al. [48] }\end{array}$ & Humidity & $\begin{array}{l}\text { SWCNT, Sodium } \\
\text { alginate, } \mathrm{CaCl}_{2}\end{array}$ & Immersion/Coating & - & $1210 \Omega / \% \mathrm{RH} @ 1 \mathrm{kHz}$ \\
\hline $\begin{array}{l}\text { Zhu et al. } \\
\text { [49] }\end{array}$ & Humidity & $\begin{array}{c}\text { Cellulose Nanofibers, } \\
\text { CNTs }\end{array}$ & Vacuum filtration & 0.5 & $\begin{array}{c}1307 \Omega / \% \text { RH @ DC } \\
\text { voltage }\end{array}$ \\
\hline $\begin{array}{l}\text { Syrový et } \\
\text { al. [52] }\end{array}$ & Humidity & $\begin{array}{c}\text { Carbon Paste } \\
\text { Cellulose nanofibril }\end{array}$ & Screen-Printing & 1 & $\begin{array}{c}\text { Up to } 122 \mathrm{k} \Omega / \% \mathrm{RH} @ \\
1 \mathrm{kHz}\end{array}$ \\
\hline $\begin{array}{l}\text { Liu et al. } \\
\text { [53] }\end{array}$ & Temperature & $\begin{array}{c}\text { Laser-Induced } \\
\text { Graphene (LIG)/Starch } \\
\text { Film }\end{array}$ & $\begin{array}{l}\text { Laser-Patterning and } \\
\text { Transferring }\end{array}$ & - & $\sim 1.2 \mathrm{k} \Omega /{ }^{\circ} \mathrm{C}$ \\
\hline $\begin{array}{c}\text { Barras et al. } \\
\quad[54]\end{array}$ & Humidity & $\begin{array}{l}\text { Carbon Filaments and } \\
\text { carboxymethyl } \\
\text { cellulose on Paper }\end{array}$ & Screen-printing & 0.7 & $\begin{array}{c}\sim 2.6 \mathrm{k} \Omega / \% \mathrm{RH} @ \mathrm{DC} \\
\text { voltage }\end{array}$ \\
\hline \multirow{3}{*}{ This work } & \multirow{3}{*}{ Humidity } & PEDOT:PSS on Paper & \multirow{3}{*}{ Screen-Printing } & \multirow{3}{*}{4} & $\begin{array}{c}217.2 \mathrm{k} \Omega / \% \mathrm{RH} @ \\
1 \mathrm{kHz}\end{array}$ \\
\hline & & PEDOT:PSS on PVA & & & 207 k $\Omega / \% R H @ 1 k H z$ \\
\hline & & Carbon Paste on Paper & & & 204 k $\Omega / \% R H @ 1 k H z$ \\
\hline
\end{tabular}




\begin{tabular}{lllll}
\hline \multirow{2}{*}{ Temperature } & PEDOT:PSS on Paper & Screen-Printing & 1.5 & $25 \Omega /{ }^{\circ} \mathrm{C} @ 10 \mathrm{kHz}$ \\
\cline { 2 - 2 } & & & & $75 \Omega /{ }^{\circ} \mathrm{C}$
\end{tabular}

257

258

259

260

261

262

263

264

265

266

267

268

269

270

271

272

273

274

275

276

277

278

279

280

281

282

283

In the case of biodegradable temperature sensors, authors like Salvatore et al. [50] and Yi et al. [51] also opted for the pattering of resistive layouts on biodegradable substrates; one of them following a UV lithography and etching process, after which the pattern is transferred to the substrate (which is a similar process to the one followed in the LIG-based sensor presented by Liu et al. [53]); and the other following a mask-aided drop casting method. It can be seen that the sensitivities of the temperature sensors presented in this work are higher than that obtained with the Mg-based and Zn-based sensors, even with smaller areas (e.g., when compare the carbon-based sensor with respect to the Mg-based one). Regarding printed sensors, although there are numerous screen-printed as well as inkjet-printed sensors reported in the literature, most of them are based on non-biodegradable materials (either the electrodes or even both electrodes and substrates). Among the few fully biodegradable sensors that can be found are the screen-printing approaches presented by Syrový et al. [52] and Barras et al. [54], which demonstrate the trend towards the use of carbon materials on cellulose-based substrates for the fabrication of fully biodegradable and printed sensors.

\subsection{Characterization as Hybrid Sensors}

Based on the results obtained for both RH and temperature sensors, the devices fabricated could be successfully employed in a hybrid sensor, where the $\mathrm{RH}$ is extracted by measuring the impedance between the terminals of IDE structure, and the temperature through one of the junctions of the IDE structure, i.e., the line that links all fingers of one IDE terminal [55]. To exemplify this concept, in Figure 7 we show a comparison between the impedance of a carbonbased line of $3 \mathrm{~mm}$ of width and the impedance of a carbon-based IDE structure on the same substrate (paper). These results show how at $1 \mathrm{kHz}$ and $10 \mathrm{kHz}$ the combination of the two measurements, at the IDE terminals and at the line ends, would provide sufficient data to isolate the effects of temperature and humidity, resulting in a biodegradable, compact, simple and costeffective multi-sensing method. 

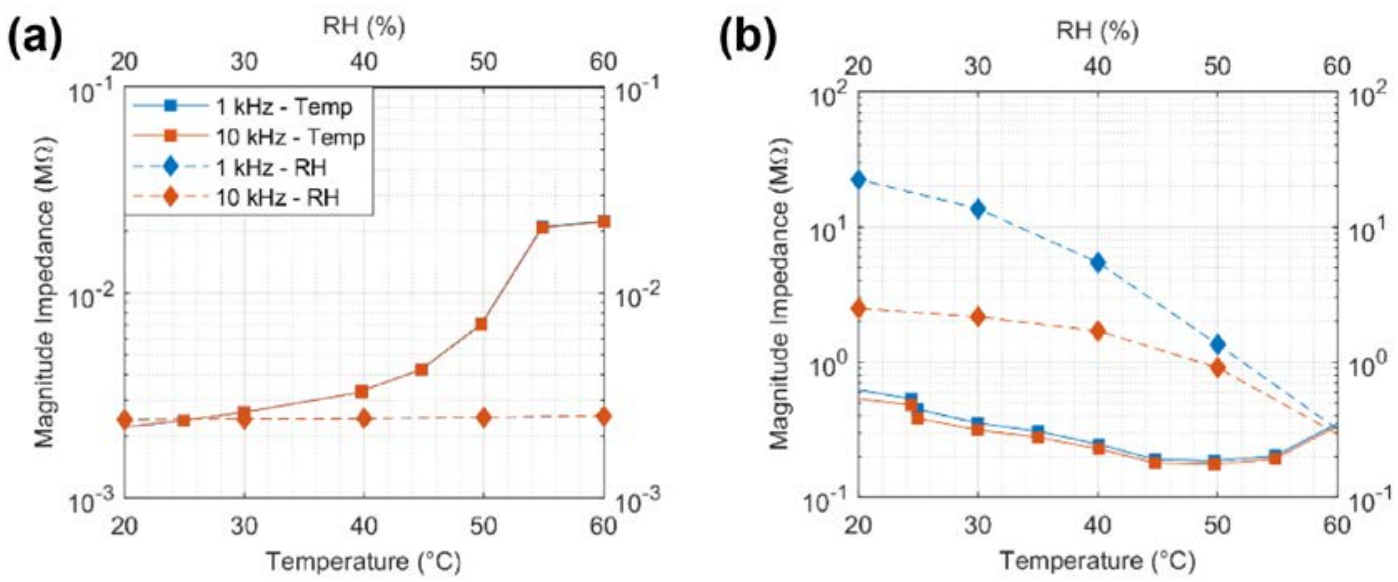

Figure 7. Impedance as a function of temperature and RH for a carbon-based line with $3 \mathrm{~mm}$ of width (a) and a carbon-based IDE structure (b), both on paper.

\section{Conclusions}

With this contribution, we intend to shift the focus of research in printed electronics and sensors towards a real sustainability of printed Internet of Things nodes. For this reason, we designed, fabricated and characterized a set of different sensors with biodegradable materials (both conductive materials and insulating substrates), in order to measure the temperature and humidity content in the environment. Our low-cost, sustainable and high throughput method allowed us to produce multi-sensing devices made of conductive polymers and a carbon-based paste on both paper and PVA substrates. The performances of these sensors are remarkable and detectable with low-cost equipment $(0.04 \%$ change in relative resistance per degree Celsius, 1 dec change in impedance per $20 \% \mathrm{RH}$ ). This factor, in combination with the facile production method and the significantly reduced environmental impact, makes this new class of sensors promising candidates for a sustainable development of sensors within the Internet of Everything paradigm.

\section{Acknowledgements}

303 This work was partially funded by the fellowship H2020-MSCA-IF-2017 794885-SELFSENS, 304 the TUM Graduate School and the Spanish Ministry of Education, Culture, and Sport through the predoctoral grant FPU16/01451. 
308

309

310

311

312

313

314

315

316

317

318

319

320

321

322

323

324

325

326

327

328

329

330

331

332

333

334

335

336

337

338

339

340

341

342

343

344

345

346

347

348

349

350

351

352

353

354

[1] N. Wang, N. Zhang, and M. Wang, "Wireless sensors in agriculture and food industryRecent development and future perspective," Computers and Electronics in Agriculture, vol. 50, no. 1, pp. 1-14, Jan. 2006, doi: 10.1016/j.compag.2005.09.003.

[2] Z. Chen and C. Lu, "Humidity Sensors: A Review of Materials and Mechanisms," Dec. 2005.

https://www.ingentaconnect.com/content/asp/senlet/2005/00000003/00000004/art00002 ?token=006c1efa37b3d953bcdeaf68263c4a6f644a467c79675d7c4e4a47543c7e386f7e2a 46762c20675d7d7067702e744a4553123b9853e5 (accessed Feb. 25, 2020).

[3] H. Farahani, R. Wagiran, and M. N. Hamidon, "Humidity Sensors Principle, Mechanism, and Fabrication Technologies: A Comprehensive Review," Sensors, vol. 14, no. 5, pp. 7881-7939, May 2014, doi: 10.3390/s140507881.

[4] F. A. Viola, A. Spanu, P. C. Ricci, A. Bonfiglio, and P. Cosseddu, "Ultrathin, flexible and multimodal tactile sensors based on organic field-effect transistors," Scientific Reports, vol. 8, no. 1, Art. no. 1, May 2018, doi: 10.1038/s41598-018-26263-1.

[5] C. Liu et al., "Highly stable pressure sensor based on carbonized melamine sponge using fully wrapped conductive path for flexible electronic skin," Organic Electronics, vol. 76, p. 105447, Jan. 2020, doi: 10.1016/j.orgel.2019.105447.

[6] C. Rullyani, M. Ramesh, C.-F. Sung, H.-C. Lin, and C.-W. Chu, "Natural polymers for disposable organic thin film transistors,” Organic Electronics, vol. 54, pp. 154-160, Mar. 2018, doi: 10.1016/j.orgel.2017.12.034.

[7] M. Irimia-Vladu, Eric. D. Głowacki, G. Voss, S. Bauer, and N. S. Sariciftci, "Green and biodegradable electronics,” Materials Today, vol. 15, no. 7, pp. 340-346, Jul. 2012, doi: 10.1016/S1369-7021(12)70139-6.

[8] M. Berggren, D. Nilsson, and N. D. Robinson, "Organic materials for printed electronics," Nature Materials, vol. 6, no. 1, Art. no. 1, Jan. 2007, doi: 10.1038/nmat1817.

[9] Y. Seekaew, S. Lokavee, D. Phokharatkul, A. Wisitsoraat, T. Kerdcharoen, and C. Wongchoosuk, "Low-cost and flexible printed graphene-PEDOT:PSS gas sensor for ammonia detection,” Organic Electronics, vol. 15, no. 11, pp. 2971-2981, Nov. 2014, doi: 10.1016/j.orgel.2014.08.044.

[10] V. Dua et al., “All-Organic Vapor Sensor Using Inkjet-Printed Reduced Graphene Oxide,” Angewandte Chemie International Edition, vol. 49, no. 12, pp. 2154-2157, 2010, doi: 10.1002/anie.200905089.

[11] S. Lim, B. Kang, D. Kwak, W. H. Lee, J. A. Lim, and K. Cho, “Inkjet-Printed Reduced Graphene Oxide/Poly(Vinyl Alcohol) Composite Electrodes for Flexible Transparent Organic Field-Effect Transistors,” J. Phys. Chem. C, vol. 116, no. 13, pp. 7520-7525, Apr. 2012, doi: 10.1021/jp203441e.

[12] F. J. Romero, A. Rivadeneyra, M. Becherer, D. P. Morales, and N. Rodríguez, "Fabrication and Characterization of Humidity Sensors Based on Graphene OxidePEDOT:PSS Composites on a Flexible Substrate,” Micromachines, vol. 11, no. 2, Art. no. 2, Feb. 2020, doi: 10.3390/mi11020148.

[13] S. Miserere, S. Ledru, N. Ruillé, S. Griveau, M. Boujtita, and F. Bedioui, "Biocompatible carbon-based screen-printed electrodes for the electrochemical detection of nitric oxide," Electrochemistry Communications, vol. 8, no. 2, pp. 238-244, Feb. 2006, doi: 10.1016/j.elecom.2005.11.016.

[14] X. Liu, M. Mwangi, X. Li, M. O’Brien, and G. M. Whitesides, "Paper-based piezoresistive MEMS sensors,” Lab Chip, vol. 11, no. 13, pp. 2189-2196, Jun. 2011, doi: 10.1039/C1LC20161A. 
[15] J. G. Bell, M. P. S. Mousavi, M. K. Abd El-Rahman, E. K. W. Tan, S. HomerVanniasinkam, and G. M. Whitesides, "Paper-based potentiometric sensing of free bilirubin in blood serum," Biosensors and Bioelectronics, vol. 126, pp. 115-121, Feb. 2019, doi: 10.1016/j.bios.2018.10.055.

[16] M. S. Verma et al., "Sliding-strip microfluidic device enables ELISA on paper," Biosensors and Bioelectronics, vol. 99, pp. 77-84, Jan. 2018, doi: 10.1016/j.bios.2017.07.034.

[17] J. N. Palasagaram and R. Ramadoss, "MEMS-Capacitive Pressure Sensor Fabricated Using Printed-Circuit-Processing Techniques,” IEEE Sensors Journal, vol. 6, no. 6, pp. 1374-1375, Dec. 2006, doi: 10.1109/JSEN.2006.884430.

[18] G. DeJean, R. Bairavasubramanian, D. Thompson, G. E. Ponchak, M. M. Tentzeris, and J. Papapolymerou, "Liquid Crystal polymer (LCP): a new organic material for the development of multilayer dual-frequency/dual-polarization flexible antenna arrays," IEEE Antennas and Wireless Propagation Letters, vol. 4, pp. 22-26, 2005, doi: 10.1109/LAWP.2004.841626.

[19] Y. Okahisa, A. Yoshida, S. Miyaguchi, and H. Yano, "Optically transparent woodcellulose nanocomposite as a base substrate for flexible organic light-emitting diode displays," Composites Science and Technology, vol. 69, no. 11, pp. 1958-1961, Sep. 2009, doi: 10.1016/j.compscitech.2009.04.017.

[20] J. Xu et al., "Conductive polypyrrole-bacterial cellulose nanocomposite membranes as flexible supercapacitor electrode,” Organic Electronics, vol. 14, no. 12, pp. 3331-3338, Dec. 2013, doi: 10.1016/j.orgel.2013.09.042.

[21] M. U. Khan, Q. M. Saqib, G. Hassan, and J. Bae, “All printed organic humidity sensor based on egg albumin,” Sensing and Bio-Sensing Research, vol. 28, p. 100337, Jun. 2020, doi: 10.1016/j.sbsr.2020.100337.

[22] S. Hajian et al., "Development of a Fluorinated Graphene-Based Resistive Humidity Sensor," IEEE Sensors Journal, vol. 20, no. 14, pp. 7517-7524, Jul. 2020, doi: 10.1109/JSEN.2020.2985055.

[23] X. Zhang et al., "Printed Carbon Nanotubes-Based Flexible Resistive Humidity Sensor," IEEE Sensors Journal, vol. 20, no. 21, pp. 12592-12601, Nov. 2020, doi: 10.1109/JSEN.2020.3002951.

[24] V. S. Turkani et al., "A highly sensitive printed humidity sensor based on a functionalized MWCNT/HEC composite for flexible electronics application,” Nanoscale Adv., vol. 1, no. 6, pp. 2311-2322, Jun. 2019, doi: 10.1039/C9NA00179D.

[25] R. Alrammouz et al., "Highly porous and flexible capacitive humidity sensor based on self-assembled graphene oxide sheets on a paper substrate," Sensors and Actuators B: Chemical, vol. 298, p. 126892, Nov. 2019, doi: 10.1016/j.snb.2019.126892.

[26] F. Güder et al., "Paper-Based Electrical Respiration Sensor," Angewandte Chemie International Edition, vol. 55, no. 19, pp. 5727-5732, 2016, doi: 10.1002/anie.201511805.

[27] S. Kanaparthi, "Pencil-drawn Paper-based Non-invasive and Wearable Capacitive Respiration Sensor," Electroanalysis, vol. 29, no. 12, pp. 2680-2684, 2017, doi: 10.1002/elan.201700438.

[28] Z. Duan et al., "Facile, Flexible, Cost-Saving, and Environment-Friendly Paper-Based Humidity Sensor for Multifunctional Applications,” ACS Appl. Mater. Interfaces, vol. 11, no. 24, pp. 21840-21849, Jun. 2019, doi: 10.1021/acsami.9b05709.

[29] Z. Ahmad, M. Abbas, I. Gunawan, R. A. Shakoor, F. Ubaid, and F. Touati, "Electrosprayed PVA coating with texture-enriched surface morphology for augmented humidity sensing,” Progress in Organic Coatings, vol. 117, pp. 7-9, Apr. 2018, doi: 10.1016/j.porgcoat.2017.12.010. 
[30] AGFA, “ORGACONTM conductive polymer screen-printing inks.” Sep. 26, 2018, Accessed: Nov. 19, 2020. [Online]. Available: https://www.agfa.com/specialtyproducts/wp-content/uploads/sites/8/2018/10/Screen-Printing-inks-2018v4.0.pdf.

[31] Henkel, “LOCTITE ECI 8001 E\&C - Technical Data Sheet.” 2017, [Online]. Available: https://dm.henkel-dam.com/is/content/henkel/lt-5980-brochure-printed-electronics-inksand-coatings.

[32] I. Moutinho, P. Oliveira, M. Figueiredo, and P. Ferreira, "EVALUATING THE SURFACE ENERGY OF SURFACE SIZED PRINTING AND WRITING PAPERS," 2007. /paper/EVALUATING-THE-SURFACE-ENERGY-OF-SURFACE-SIZED-ANDMoutinho-Oliveira/28fbc81c4a81cf2ad545e3434d55cba27214c526 (accessed Nov. 19, 2020).

[33] DuPont Teijin Films, “MELINEX® ST506.” Mar. 24, 2016, Accessed: Nov. 19, 2020. [Online]. Available: https://usa.dupontteijinfilms.com/wpcontent/uploads/2017/01/ST506-Datasheet.pdf.

[34] F. J. Romero et al., "Design, fabrication and characterization of capacitive humidity sensors based on emerging flexible technologies," Sensors and Actuators B: Chemical, vol. 287, pp. 459-467, May 2019, doi: 10.1016/j.snb.2019.02.043.

[35] A. Rivadeneyra, J. Fernández-Salmerón, J. Banqueri, J. A. López-Villanueva, L. F. Capitan-Vallvey, and A. J. Palma, "A novel electrode structure compared with interdigitated electrodes as capacitive sensor,” Sensors and Actuators B: Chemical, vol. 204, pp. 552-560, Dec. 2014, doi: 10.1016/j.snb.2014.08.010.

[36] A. Rivadeneyra et al., "Cost-Effective PEDOT:PSS Temperature Sensors Inkjetted on a Bendable Substrate by a Consumer Printer,” Polymers, vol. 11, no. 5, Art. no. 5, May 2019, doi: 10.3390/polym11050824.

[37] X. He et al., "Hexagonal and Square Patterned Silver Nanowires/PEDOT:PSS Composite Grids by Screen Printing for Uniformly Transparent Heaters,” Polymers, vol. 11, no. 3, Art. no. 3, Mar. 2019, doi: 10.3390/polym11030468.

[38] S. K. M. Jönsson et al., "The effects of solvents on the morphology and sheet resistance in poly(3,4-ethylenedioxythiophene)-polystyrenesulfonic acid (PEDOT-PSS) films," Synthetic Metals, vol. 139, no. 1, pp. 1-10, Aug. 2003, doi: 10.1016/S03796779(02)01259-6.

[39] A. Denneulin, A. Blayo, J. Bras, and C. Neuman, "PEDOT:PSS coating on specialty papers: Process optimization and effects of surface properties on electrical performances," Progress in Organic Coatings, vol. 63, no. 1, pp. 87-91, Jul. 2008, doi: 10.1016/j.porgcoat.2008.04.009.

[40] P. Wilson, C. Lekakou, and J. F. Watts, "A comparative assessment of surface microstructure and electrical conductivity dependence on co-solvent addition in spin coated and inkjet printed poly(3,4-ethylenedioxythiophene):polystyrene sulphonate (PEDOT:PSS),” Organic Electronics, vol. 13, no. 3, pp. 409-418, Mar. 2012, doi: 10.1016/j.orgel.2011.11.011.

[41] A. Albrecht, J. F. Salmeron, M. Becherer, P. Lugli, and A. Rivadeneyra, "Screen-Printed Chipless Wireless Temperature Sensor,” IEEE Sensors Journal, vol. 19, no. 24, pp. 12011-12015, Dec. 2019, doi: 10.1109/JSEN.2019.2940836.

[42] J. Mamouni and L. Yang, "Interdigitated microelectrode-based microchip for electrical impedance spectroscopic study of oral cancer cells,” Biomed Microdevices, vol. 13, no. 6, pp. 1075-1088, Dec. 2011, doi: 10.1007/s10544-011-9577-8.

[43] Y. Feng, J. Hallstedt, Q. Chen, L.-R. Zheng, and Y. Huang, "Development and experimental verification of analytical models for printable interdigital capacitor sensors on paperboard," in 2009 IEEE SENSORS, Oct. 2009, pp. 1034-1039, doi: 10.1109/ICSENS.2009.5398531. 
[44] Y. Zhang and Y. Cui, "Development of Flexible and Wearable Temperature Sensors Based on PEDOT:PSS,” IEEE Transactions on Electron Devices, vol. 66, no. 7, pp. 31293133, Jul. 2019, doi: 10.1109/TED.2019.2914301.

[45] W. Honda, S. Harada, T. Arie, S. Akita, and K. Takei, "Printed wearable temperature sensor for health monitoring," in 2014 IEEE SENSORS, Nov. 2014, pp. 2227-2229, doi: 10.1109/ICSENS.2014.6985483.

[46] J. Maslik, H. Andersson, V. Forsberg, M. Engholm, R. Zhang, and H. Olin, "PEDOT:PSS temperature sensor ink-jet printed on paper substrate," J. Inst., vol. 13, no. 12, pp. C12010-C12010, Dec. 2018, doi: 10.1088/1748-0221/13/12/C12010.

[47] M. Yang and M. Zhang, "Biodegradation of Carbon Nanotubes by Macrophages," Front. Mater., vol. 6, 2019, doi: 10.3389/fmats.2019.00225.

[48] I. L. Liakos, A. Mondini, C. Filippeschi, V. Mattoli, F. Tramacere, and B. Mazzolai, "Towards ultra-responsive biodegradable polysaccharide humidity sensors," Materials Today Chemistry, vol. 6, pp. 1-12, Dec. 2017, doi: 10.1016/j.mtchem.2017.08.001.

[49] P. Zhu et al., "Flexible and Highly Sensitive Humidity Sensor Based on Cellulose Nanofibers and Carbon Nanotube Composite Film,” Langmuir, vol. 35, no. 14, pp. 48344842, Apr. 2019, doi: 10.1021/acs.langmuir.8b04259.

[50] G. A. Salvatore et al., "Biodegradable and Highly Deformable Temperature Sensors for the Internet of Things,” Advanced Functional Materials, vol. 27, no. 35, p. 1702390, 2017, doi: 10.1002/adfm.201702390.

[51] N. Yi et al., "Fully Water-Soluble, High-Performance Transient Sensors on a Versatile Galactomannan Substrate Derived from the Endosperm,” ACS Appl. Mater. Interfaces, vol. 10, no. 43, pp. 36664-36674, Oct. 2018, doi: 10.1021/acsami.8b11682.

[52] T. Syrový et al., "Wide range humidity sensors printed on biocomposite films of cellulose nanofibril and poly(ethylene glycol)," Journal of Applied Polymer Science, vol. 136, no. 36, p. 47920, 2019, doi: https://doi.org/10.1002/app.47920.

[53] H. Liu et al., "Flexible and Degradable Multimodal Sensor Fabricated by Transferring Laser-Induced Porous Carbon on Starch Film,” ACS Sustainable Chem. Eng., vol. 8, no. 1, pp. 527-533, Jan. 2020, doi: 10.1021/acssuschemeng.9b05968.

[54] R. Barras, I. Cunha, D. Gaspar, E. Fortunato, R. Martins, and L. Pereira, "Printable cellulose-based electroconductive composites for sensing elements in paper electronics," Flex. Print. Electron., vol. 2, no. 1, p. 014006, Mar. 2017, doi: 10.1088/2058-8585/aa5ef9.

[55] A. Rivadeneyra, J. Fernández-Salmerón, M. Agudo-Acemel, J. A. López-Villanueva, L. F. Capitán-Vallvey, and A. J. Palma, "Hybrid Printed Device for Simultaneous Vapors Sensing,” IEEE Sensors Journal, vol. 16, no. 23, pp. 8501-8508, Dec. 2016, doi: 10.1109/JSEN.2016.2606415. 
492 Fabrication and characterization of fully printed biodegradable sensors for humidity and 493 temperature sensing. These sensors will contribute enormously to pave the way to more 494 cost-effective and environmental friendly devices.

495 Keywords: carbon; humidity; paper; PVA; PEDOT:PSS; screen-printing; temperature

496 Aniello Falco, Philipp S. Sackenheim, Francisco J. Romero, Markus Becherer, Paolo Lugli, 497 José F. Salmeron, Almudena Rivadeneyra*

498 Fabrication of low cost and low impact RH and temperature sensors, for the Internet of 499 Environmental-Friendly Things

500

501

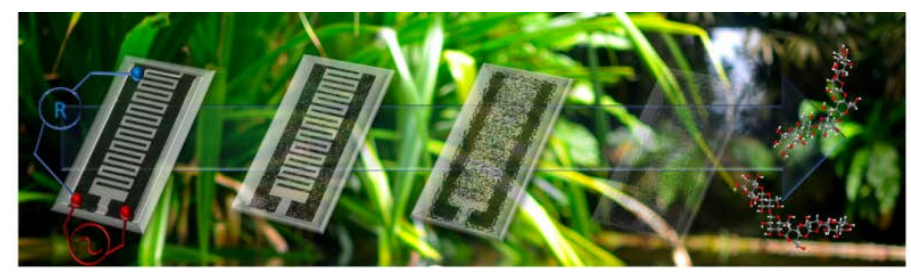

503

504

505 